\title{
Fish consumption, contaminants and sudden unexpected death in epilepsy: many more benefits than risks
}

\author{
Scorza, FA. ${ }^{\mathrm{a} *}$, Cysneiros, RM. ${ }^{\mathrm{b}}$, Arida, RM. ${ }^{\mathrm{c}}$, Terra, $V C .{ }^{\mathrm{d}}$, \\ Machado, HR. ${ }^{\mathrm{d}}$, Rabello, GMM. ${ }^{\mathrm{a}}$, Albuquerque, M. ${ }^{\mathrm{a}}$ and Cavalheiro, EA. ${ }^{\mathrm{a}}$ \\ a Disciplina de Neurologia Experimental, Universidade Federal de São Paulo - UNIFESP, \\ Escola Paulista de Medicina - EPM, Rua Botucatu, 862, Edifício Leal Prado, \\ CEP 04023-900, São Paulo, SP, Brazil \\ 'Programa de Pós-Graduação em Distúrbios do Desenvolvimento, \\ Centro de Ciências Biológicas e da Saúde, Universidade Presbiteriana Mackenzie, São Paulo, Brazil

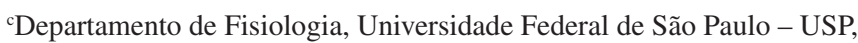 \\ Escola Paulista de Medicina - EPM, Universidade Federal de São Paulo - UNIFESP, São Paulo, Brazil \\ ${ }^{\mathrm{d} C e n t r o ~ d e ~ C i r u r g i a ~ d e ~ E p i l e p s i a ~-~ C I R E P, ~ D e p a r t a m e n t o ~ d e ~ N e u r o l o g i a, ~ P s i q u i a t r i a ~ e ~ P s i c o l o g i a ~ M e ́ d i c a, ~}$ \\ Faculdade de Medicina de Ribeirão Preto, Universidade de São Paulo - USP, \\ Ribeirão Preto, São Paulo, Brazil \\ Received November 11, 2009 - Accepted January 12, 2010 - Distributed August 31, 2010 \\ *e-mail: scorza.nexp@epm.br \\ (With 1 figure)

\begin{abstract}
People with epilepsy have an increased risk of dying prematurely and the most common epilepsy-related category of death is sudden unexpected death in epilepsy (SUDEP). SUDEP is mainly a problem for patients with chronic uncontrolled epilepsy. The ultimate goal of research in SUDEP is to develop new methods to prevent it and actions other than medical and surgical therapies that could be very useful. Nutritional aspects, i.e., omega- 3 fatty acids deficiency, could have an interesting role in this scenario. Some animal and clinical studies have suggested that omega- 3 fatty acids could be useful in the prevention and treatment of epilepsy and hence SUDEP. It has been ascertained that the only foods that provide large amounts of omega-3 are seafood (fish and shellfish); however, some fish are contaminated with methylmercury, which may counteract the positive effects of omega- 3 fatty acids. Our update review summarises the knowledge of the role of fish consumption on epilepsy research.
\end{abstract}

Keywords: epilepsy, omega-3, heart, sudden death, fish consumption.

\section{Consumo de peixe, contaminantes e morte súbita em epilepsia: mais benefícios do que riscos}

\section{Resumo}

Pessoas com epilepsia têm um risco aumentado de morrer de forma prematura e a causa mais comum de morte relacionada à epilepsia encontra-se na categoria de morte súbita inesperada em epilepsia (SUDEP). SUDEP é um problema significativo para pacientes com epilepsia crônica não controlada. O principal objetivo nas pesquisas em SUDEP é o desenvolvimento de métodos capazes de levar à sua prevenção e ações outras que não medicamentosas e cirúrgicas que podem ser úteis. Os aspectos nutricionais, como por exemplo, a deficiência do ácido graxo ômega-3 pode ter um papel interessante neste cenário. Alguns estudos animais e clínicos têm sugerido que os ácidos graxos ômega-3 podem ser úteis na prevenção e no tratamento da epilepsia e, consequentemente, na SUDEP. Os únicos alimentos que contêm grandes proporções de ômega-3 são os frutos do mar (peixes e mariscos). No entanto, alguns peixes podem estar contaminados com metilmercúrio, o que pode levar a um efeito contrário ao benefício trazido pelos ácidos graxos ômega-3. Aqui, resumimos o conhecimento do papel do consumo de peixe nas pesquisas em epilepsia.

Palavras-chave: epilepsia, ômega-3, coração, morte súbita, consumo de peixe. 


\section{Sudden Unexpected Death in Epilepsy: General View}

Epilepsy is one of the most common neurologic problems worldwide (Chang and Lowenstein, 2003). Approximately 2 million people in the United States have epilepsy, and 3 percent of people in the general population will have epilepsy at some point in their lives (Chang and Lowenstein, 2003). Prevalence in Brazil was determined in small populations and is about 8.2/1.000 inhabitants (Borges et al., 2004). Unfortunately, individuals with epilepsy are at higher risk of death than the general population and sudden unexpected death in epilepsy (SUDEP) is the most important direct epilepsy-related cause of death (Stollberger and Finsterer, 2004). SUDEP is responsible for 7.5 to $17 \%$ of all deaths in epilepsy and has an incidence among adults between 1:500 and 1:1,000 patient-years (Schuele et al., 2007). SUDEP is defined by precise criteria that were approved in 1997 by an expert panel and is designated as sudden, unexpected, witnessed or unwitnessed, non-traumatic and non-drowning deaths in patients with epilepsy, with or without evidence of a seizure and excluding documented status epilepticus, in which post mortem examination does not reveal a toxicological or anatomical cause of death (Nashef, 1997).

A number of associated factors for SUDEP have been reported but the results are not wholly consistent between studies. These include refractoriness of the epilepsy, presence of generalised tonic-clonic seizures, polytherapy with antiepileptic drugs, young age, duration of the seizure disorder ranging from 15 to 20 years, early onset of epilepsy and winter temperatures (Stollberger and Finsterer, 2004; Scorza et al., 2007). Additionally, potential pathomechanisms for SUDEP are unknown, but it is very probable that cardiac arrhythmia during and between seizures plays a potential role (Stollberger and Finsterer, 2004). Over the past two decades, important advances have been made concerning SUDEP. However, our understanding of the exact mechanisms underlying SUDEP and the best way to prevent it, are still incomplete.

\section{Possible Cardiac Abnormalities Related to Sudden Unexpected Death in Epilepsy}

$A$ better understanding of the mechanisms of SUDEP is essential. As already discussed, the cause of death in SUDEP is currently unknown; however, a number of postmortem, ictal and interictal cardiac abnormalities account for the possibility of seizure-induced cardiogenic SUDEP (Stollberger and Finsterer, 2004; Ryvlin et al., 2006).

Postmortem examinations: In some SUDEP patients, a dilated and heavier than expected heart was found (Stollberger and Finsterer, 2004; Bell and Sander, 2006; Colugnati et al., 2005). Furthermore, pathological alterations in the heart of SUDEP cases have also been described, such as fibrosis of the walls of small coronary arteries, atrophy of cardiomyocytes, myofibrillar degeneration, edema of the conductive tissue and morphological abnormalities of the cardiac conduction system (Stollberger and Finsterer, 2004; Bell and Sander, 2006; Colugnati et al., 2005). These abnormalities may be the consequence of repeated hypoxemia and/or an associated increase of catecholamines during ictal sympathetic storm (Stollberger and Finsterer, 2004; Bell and Sander, 2006; Colugnati et al., 2005).

Ictal period: Several studies have assessed the frequency and character of ictal cardiac rhythm during seizures (Stollberger and Finsterer, 2004; Ryvlin et al., 2006; Lathers et al., 2008) and compelling evidence exists for the presence of ictal arrhythmias (Ryvlin et al., 2006). For instance, Nashef et al. (1996) recorded non-invasively ictal cardiorespiratory variables in patients with epilepsy. They found an increase in heart rate in $91 \%$ of 41 seizures monitored, and a transient bradycardia in five seizures (four patients). Moreover, Nei et al. (2000) evaluated the electrocardiographic (ECG) changes in fifty-one seizures in 43 patients with refractory epilepsy. They showed that seventy percent of patients had either ECG abnormalities $(16 \%)$ or tachycardia $(30 \%)$ or both $(23 \%)$ during the ictal and/or post-ictal period. All authors suggest that these changes may be relevant to the pathophysiology of SUDEP.

Interictal period: Cardiac investigations between seizures have been described by several research groups. Drake et al. (1993) reviewed resting ECGs in 75 patients with epilepsy and compared ventricular rate, PR interval, QRS duration, and QT interval corrected for heart rate (QTC) with normal ECGs recorded in age-matched patients without cardiac or neurologic disorders. Epilepsy patients showed a higher heart rate and a longer QT duration than ECGs recorded in age-matched patients without a cardiac or neurologic disorder. However, heart rate and QT duration were not outside the normal range. In 2003, Tigaran et al. (2003) investigated whether patients with drug refractory epilepsy have cardiovascular abnormalities that might be related to a high frequency of sudden death. In their study, twenty-three patients underwent comprehensive cardiovascular evaluations (ECG, Holter-monitoring, echocardiography, ergometric exercise test and myocardial scintigraphy, and, if abnormalities were found, coronary angiography) before and during video-EEG monitoring. They found ST-segment depression in $40 \%$ of patients, which were associated with a higher maximum heart rate during seizures, suggesting that cardiac ischemia may occur in these patients (Tigaran et al., 2003). Although interictal changes in heart rate variability have been described in patients with epilepsy, their contribution to SUDEP remains to be determined (Tomson et al., 2008).

\section{The Potential Role of Omega-3 in the Management of Epilepsy}

Beneficial effects of omega- 3 fatty acids on the cardiovascular system have been postulated. Several studies have shown that omega-3 fatty acids have protective effects in preventing coronary heart disease, reducing arrhythmias and thrombosis, lowering plasma triglyceride 
levels and reducing blood clotting tendency (Smith and Sahyoun, 2005). Furthermore, substantial evidence from epidemiological and case-control studies indicates that omega-3 reduces the risk of cardiovascular mortality, with an especially potent effect on sudden cardiac death (Calder, 2004).

Concerning epilepsies, although the availability of pharmacological treatment of this neurological condition has expanded, antiepileptic drugs are still limited in clinic efficacy. Several genetic, environmental and social factors can contribute to the inefficacy of therapeutic outcomes in patients with epilepsy. Among these factors, nutritional aspects, i.e., omega- 3 fatty acids deficiency may have an interesting role. Some animal and clinical studies have indicated that omega-3 fatty acids could be useful in the prevention/treatment of epilepsy, as well as having a possible effect in the prevention of cardiovascular abnormalities and a reduction of occurrence of SUDEP (Taha et al., 2009; Scorza et al., 2008; DeGiorgio et al., 2008).

In 1998, Voskuyil and colleagues, using the cortical stimulation seizure model in rats, demonstrated a modest anticonvulsant effect with a long duration as a result of the administration of polyunsaturated fatty acids. Moreover, pharmacology studies show that polyunsaturated fatty acids applied extracellularly raise the stimulatory thresholds of CA1 neurons in hippocampal slices (Xiao and Li, 1999). Recently, our group was the first to demonstrate that a chronic treatment with omega- 3 fatty acids promoted neuroprotection and increased parvalbumin-positive neurons in the hippocampal formation of rats with epilepsy (Ferrari et al., 2008), suggesting that omega-3 fatty acids administration leads to prominent positive plastic changes in the hippocampal formation of rats with epilepsy. In this line, Puri et al.(2007) demonstrated a decrease in phosphodiesters in patients with epilepsy supplemented with omega-3. In a clinical study, Schlanger et al. (2002) reported on an open trial in which 5 patients took omega-3 supplements. In that study, a special spread containing $65 \%$ omega- 3 fatty acids was added to the daily diet of five patients with epilepsy. The patients consumed $5 \mathrm{~g}$ of this spread at every breakfast for 6 months and all of them showed a marked reduction in both frequency and strength of epileptic seizures, suggesting that a dietary supplement containing omega-3 may be beneficial for the suppression of some cases of epileptic seizures. Recently the first randomized, placebo-controlled parallel trial of omega-3 supplementation in 57 patients with refractory epilepsy, seizure frequency was reduced over the first 6 weeks of treatment in the supplemented group, but this effect was not sustained over the 12 week total trial (Yuen and Sander, 2004). The authors believe that the loss of effect following the initial 6 weeks is a result of omega-3 preparations, doses, treatment duration, and sample sizes. Specifically, the researchers used in their study a total daily dose of approximately $1.7 \mathrm{~g}$ omega-3 (approx $1 \mathrm{~g}$ eicosapentaenoic acid (EPA) and $0.7 \mathrm{~g}$ docosahexaenoic acid (DHA)), but believe that higher doses and different omega-3 ratios should be tested.
As omega-3 fatty acids per se have been shown in some studies to reduce cardiac arrhythmias and sudden cardiac deaths (Calder, 2004), Yuen and Sander (2004) proposed the interesting hypothesis that omega-3 fatty acid supplementation in patients with refractory seizures may not only reduce seizures but also reduce cardiac arrhythmias and hence SUDEP. Two experimental studies developed by our group could better reinforce this hypothesis. Firstly, we evaluated the heart rate, in vivo (ECG) and isolated ex vivo preparation (Langendorf preparation) of rats with epilepsy (Colugnati et al., 2005). Our results showed significant differences in the mean heart rate in vivo between the groups. In contrast, we did not find differences in the isolated ex vivo situation, suggesting a central nervous system modulation of the heart, which could explain sudden unexpected death in epilepsy. Scorza et al. (unpublished data) performed a similar set of experiments (heart rate in vivo and isolated ex vivo preparation) of rats with epilepsy before and after chronic omega- 3 administration. The results showed differences in the mean heart rate in vivo, but surprisingly, no differences in heart rate could be observed in the isolated ex vivo condition.

It has been suggested that the use of certain antiepileptic drugs (AEDs), especially carbamazepine (CBZ), may give rise to a predisposition to SUDEP (Stollberger and Finsterer, 2004). Furthermore, CBZ has been shown to affect the autonomic nervous system and the conduction system of the heart, mainly when associated with elevated plasma drug levels above $40 \mu \mathrm{mol} . \mathrm{L}^{-1}$ (Stollberger and Finsterer, 2004). According to this, Yuen et al. (2008) reported very recently the fatty acid (FA) profiles in red blood cells (RBCs) and plasma obtained prior to and following omega-3 FA supplementation in 56 patients with epilepsy, providing an opportunity to examine potential effects of AEDs on FA profiles. They showed that patients on CBZ exhibited a less favorable FAs profile, associated with a greater risk of coronary heart disease mortality. In sum, the authors concluded that as arrhythmias are thought to be an important mechanism in coronary heart disease mortality and sudden unexplained death in epilepsy (SUDEP), the effect of CBZ effect in reducing omega-3 FAs might potentially explain some cases of SUDEP among patients prescribed CBZ.

Taking all data together, the first randomized, placebocontrolled parallel group study of omega-3 supplementation in patients with chronic epilepsy showed only a transient effect on seizure frequency that was not confirmed by another research group, but additional trials are required (Scorza et al., 2008; DeGiorgio and Miller, 2008). These results did not totally confirm that omega-3 fatty acids reduce the frequency of epileptic seizures in patients with intractable epilepsy; however, they established the safety of omega-3 supplementation in people with epilepsy (DeGiorgio and Miller, 2008). Quite interestingly, there is now great interest in n-3 fatty acids for the prevention of SUDEP (Scorza et al., 2008; DeGiorgio and Miller, 2008) and we have to bear in mind that as omega- 3 fatty acids per se have been shown to reduce cardiac arrhythmias and sudden cardiac deaths, it could be suggested that omega-3 
fatty acid supplementation in patients with refractory seizures may reduce seizures and seizure-associated cardiac arrhythmias and hence SUDEP. However, it is very important to emphasize that nutritional therapy (e.g., omega-3 supplementation) is not a substitute for anticonvulsant medications.

\section{Polyunsaturated Fatty Acids in the Diet}

Polyunsaturated fatty acids are present at high levels in the brain (Ohara, 2007). The 04 polyunsaturated fatty acids are designated eicopentanoic acid (EPA) and decosahexanoic acid (DHA), which are n-3 fatty acids (omega-3); and dihomogammalinolenic acid (DGLA) and arachidonic acid (AA), which are n-6 fatty acids (omega-6), comprise over $10 \%(\mathrm{w} / \mathrm{w})$ of the dry weight of the brain (Ohara, 2007; Calon and Cole, 2007).Fish and fish oil long chain omega-3 fatty acids may interfere with certain nervous system diseases (Ferrari et al, 2008; Bourre, 2004). Omega-3 fatty acids are important for the treatment and prevention of cardiovascular and neurological diseases, and a diet rich in fish may be a good way to improve the development of the brain (Table 1) (Ferrari et al, 2008; Bourre, 2004). The only foods that provide large amounts of omega- 3 are seafood (fish and shellfish - Figure 1).

Undeniably, fish is very good for us. However, some kinds of fish contain contaminants such as methylmercury (Smith, 2005; Jeejeebhoy, 2008; Clarkson and 2003) that is strongly neurotoxic, specially for infants (Smith and Sahuoun, 2005; Jeejeebhoy, 2008; Clarkson et al, 2003). Considering this, the consumption of non predatory fish should be the best choice (Jeejeebhoy, 2008; no authors, 2007) (Table 2). Taking into account species usually consumed in Brazil, sardines should be considered the first choice, because of its low methyl mercury concentration.

\section{Final Considerations}

The risk of sudden death is clearly greater in the epilepsy population, and SUDEP is the commonest seizurerelated category (Stollberger and Finsterer, 2004; Tomson et al., 2008; Scorza et al., 2008; Yuen and Sander, 2004).

Table 1. Safe and effective doses of omega-3 fatty acids for adults. Adapted by permission from Dr. Marianna Mazza.

\section{EPA and DHA}

- The adequate daily intake of EPA and DHA for adults should be at least $220 \mathrm{mg}$ of each per day.

- Two to three servings of fatty fish per week (roughly $1250 \mathrm{mg}$ EPA and DHA per day) are generally recommended to treat psychiatric and neurological disorders.

\section{Fish oil supplements}

- 3000 to $4000 \mathrm{mg}$ standardised fish oils per day (this amount corresponds to roughly 2 to 3 servings of fatty fish per week).

- Typically, a $1000 \mathrm{mg}$ fish oil capsule has $180 \mathrm{mg}$ EPA and $120 \mathrm{mg}$ DHA.
Furthermore, SUDEP is mainly, but not exclusively, a problem for patients with chronic uncontrolled epilepsy (Stollberger and Finsterer, 2004; Tomson et al., 2008). In this sense, the ultimate goal of research in SUDEP is to develop new methods to prevent it, alongside actions other than medical and surgical therapies, which could be very useful in this scenario. At present, a number of different dietary modifications and nutritional supplements may help prevent seizures or improve other aspects of health in patients with epilepsy (McElroy-Cox, 2009; Gaby, 2007; Schlanger et al., 2002). In particular, our group is quite convinced that omega-3 fatty acids are very important for the normal functioning of the brain and more than this, in patients with refractory epilepsy, they may help reduce seizures and seizure-associated cardiac arrhythmias and hence, SUDEP.

Finally, fish is one of the most important foods we can choose for cardiovascular and brain health. The type of fish and seafood, the frequency of consumption, and the meal size are all essential issues in the balance of benefits and risks of regular consumption (Domingo, 2007). On the other hand, for individuals who want a diet with zero methylmercury but would like to enjoy the benefits of omega-3 fatty acids, there are always fish oil supplements

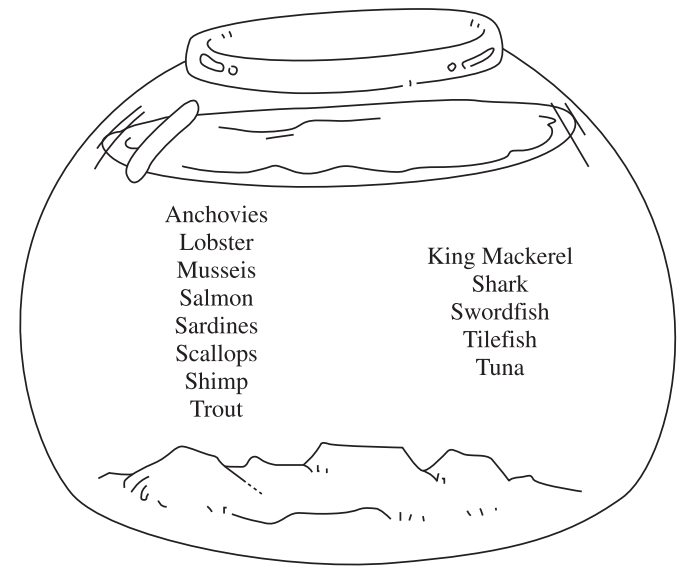

Figure 1. Top 13 fish and shell fish rich in omega-3 fatty acids.

Table 2. Top 13 fish and shell fish rich in omega-3 fatty acids considering methyl mercury concentration.

\begin{tabular}{cc}
\hline \multicolumn{2}{c}{ Methyl mercury concentration } \\
\hline Low & High \\
\hline Anchovies & King Mackerel \\
Lobster & Shark \\
Mussels & Swordfish \\
Salmon & Tilefish \\
Sardines & Tuna \\
Scallops & - \\
Shrimp & - \\
Trout & - \\
\hline
\end{tabular}


or intake of foods such as walnuts or oils (flax, canola and soybean) (Jeejeebhoy, 2008; Domingo, 2007).16,275

Acknowledgements - FAPESP, CInAPCe-FAPESP, CNPq for supporting this study.

\section{References}

BELL, GS. and SANDER, JW. 2006. Sudden unexpected death in epilepsy. Risk factors, possible mechanisms and prevention: a reappraisal. Acta Neurologica Taiwanica, vol. 15, no. 20, p. $72-83$.

BOURRE, JM. 2004. Roles of unsaturated fatty acids (especially omega-3 fatty acids) in the brain at various ages and during ageing. Journal of Nutrition, Health and Aging, vol. 8, no. 3, p. $163-174$.

CALDER, PC. 2004. n-3 fatty acids and cardiovascular disease: evidence explained and mechanisms explored. Clinical Science, vol. 107 , no. 1 , p. 1-11.

CALON, F. and COLE, G. 2007. Neuroprotective action of omega-3 polyunsaturated fatty acids against neurodegenerative diseases: evidence from animal studies. Prostaglandins, Leukotrienes \& Essential Fatty Acids, vol. 77, no. 5-6, p. 287-293

CHANG, BS. and LOWENSTEIN, DH. 2003. Epilepsy. New England Journal of Medicine, vol. 349, no. 13, p. 1257-1266.

CLARKSON, TW., MAGOS, L. and MYERS, GJ. 2003. The toxicology of mercury-current exposures and clinical manifestations. New England Journal of Medicine, vol. 349, no. 18 , p. $1731-1737$.

COLUGNATI, DB., GOMES, PA., ARIDA, RM., ALBUQUERQUE, M., CYSNEIROS, RM., CAVALHEIRO, EA. and SCORZA, FA. 2005. Analysis of cardiac parameters in animals with epilepsy: possible cause of sudden death? Arquivos de Neuropsiquiatria, vol. 63, no. 4, p. 1035-1041.

DEGIORGIO, CM., MILLER, P., MEYMANDI, S. and GORNBEINJA, JA. 2008. n-3 fatty acids (fish oil) for epilepsy, cardiac risk factors, and risk of SUDEP: clues from a pilot, double-blind, exploratory study. Epilepsy Behavior, vol. 13, no. 4, p. 681-684.

DEGIORGIO, CM. and MILLER, P. 2008. n-3 fatty acids (eicosapentanoic and docosahexanoic acids) in epilepsy and for the prevention of sudden unexpected death in epilepsy. Epilepsy Behavior, vol. 13, no. 4, p. 712-713.

DOMINGO, JL. 2007. Omega-3 fatty acids and the benefits of fish consumption: is all that glitters gold? Environmental International, vol. 33, no. 7, p. 993-998.

DRAKE, ME., REIDER, CR. and KAY, A. 1993. Electrocardiography in epilepsy patients without cardiac symptoms. Seizure, vol. 2, no. 1 , p. 63-65.

FERRARI, D., CYSNEIROS, RM., SCORZA, CA., ARIDA, RM., CAVALHEIRO, EA., ALMEIDA, ACG. and SCORZA, FA. 2008. Neuroprotective activity of omega-3 fatty acids against epilepsy-induced hippocampal damage: quantification with immunohistochemical for calcium-binding proteins. Epilepsy Behavior, vol. 13, no. 1, p. 36-42.

FISH: friend or foe? 2007. Harvard Heart Letter, vol. 17, no. 6, p. 4-6.
GABY, AR. 2007. Natural approaches to epilepsy. Alternative Medicine Review, vol. 12, no. 1, p. 9-24.

JEEJEEBHOY, KN. 2008. Benefits and risks of a fish diet--should we be eating more or less? Nature Clinical Practice Gastroenterology \& Hepatology, vol. 5, no. 4, p. 178-179.

LATHERS, CM., SCHRAEDER, PL. and BUNGO, MW. 2008. The mystery of sudden death: mechanisms for risks. Epilepsy Behavior, vol. 12, no. 1, p. 3-24.

MAZZA, M., POMPONI, M., JANIRI, L., BRIA, P. and MAZZA, S. 2007. Omega-3 fatty acids and antioxidants in neurological and psychiatric diseases: an overview. Progress in Neuropsychopharmacology Biological Psychiatry, vol. 31, no. 1 , p. 12-26.

MCELROY-COX, C. 2009. Alternative approaches to epilepsy treatment. Current Neurology and Neuroscience Reports, vol. 9 , no. 4 , p. 313-318.

NASHEF, L., WALKER, F., ALLEN, P., SANDER, JW., SHORVON, SD. and FISH, DR. 1996. Apnoea and bradycardia during epileptic seizures: relation to sudden death in epilepsy. Journal of Neurology, Neurosurgery and Psychiatry, vol. 60, no. 3, p. 297-300.

NASHEF, L. 1997. Sudden unexpected death in epilepsy: terminology and definitions. Epilepsia, vol. 38, supl. 11, p. S6-S8.

NEI, M., HO, RT. and SPERLING, MR. 2000. EKG abnormalities during partial seizures in refractory epilepsy. Epilepsia, vol. 41, no. 5 , p. $542-548$.

OHARA, K. 2007. The n-3 polyunsaturated fatty acid/dopamine hypothesis of schizophrenia. Progress in Neuropsychopharmacology Biological Psychiatry, vol. 31, no. 2, p. 469-474.

PURI, BK., KOEPP, MJ., HOLMES, J., HAMILTON, G. and YUEN, AW. 2007. A 31-phosphorus neurospectroscopy study of omega-3 long-chain polyunsaturated fatty acid intervention with eicosapentaenoic acid and docosahexaenoic acid in patients with chronic refractory epilepsy. Prostaglandins, Leukotrienes \& Essential Fatty Acids, vol. 77, no. 2, p. 105-107.

RYVLIN, P., MONTAVONT, A. and KAHANE, P. 2006. Sudden unexpected death in epilepsy: from mechanisms to prevention. Current Opinion in Neurology, vol. 19, no. 2, p. 194-199.

SCHLANGER, S., SHINITZKY, M. and YAM, D. 2002. Diet enriched with omega-3 fatty acids alleviates convulsion symptoms in epilepsy patients. Epilepsia, vol. 43, no. 1, p. 103-104.

SCHUELE, SU., WIDDESS-WALSH, P., BERMEO, A. and LÜDERS, HO. 2007. Sudden unexplained death in epilepsy: the role of the heart. Cleveland Clinic Journal of Medicine vol. 74, supl. 1, p. S121-127.

SCORZA, FA., CYSNEIROS, RM., ARIDA, RM., TERRABUSTAMANTE, VC., ALBUQUERQUE, M. and CAVALHEIRO, EA. 2008. The other side of the coin: beneficiary effect of omega-3 fatty acids in sudden unexpected death in epilepsy. Epilepsy Behavior, vol. 13, no. 2, p. 279-283.

SCORZA, FA., ALBUQUERQUE, M., ARIDA, RM. and CAVALHEIRO, EA. 2007. Sudden unexpected death in epilepsy: are winter temperatures a new potential risk factor? Epilepsy Behavior, vol. 10, no. 3, p. 509-510.

SMITH, KM. and SAHYOUN, NR. 2005. Fish consumption: recommendations versus advisories, can they be reconciled? Nutrition Review, vol. 63, no. 2, p. 39-46. 
STOLLBERGER, C. and FINSTERER, J. 2004. Cardiorespiratory findings in sudden unexplained/unexpected death in epilepsy (SUDEP). Epilepsy Research, vol. 59, no. 1, p. 51-60.

TAHA, AY., CIOBANU, FA., SAXENA, A. and MCINTYREBURNHAM, W. 2009. Assessing the link between omega-3 fatty acids, cardiac arrest, and sudden unexpected death in epilepsy. Epilepsy Behavior, vol. 14, no. 1, p. 27-31.

TIGARAN, S., MOLGAARD, H., MCCLELLAND, R., DAM, M. and JAFFE, AS. 2003. Evidence of cardiac ischemia during seizures in drug refractory epilepsy patients. Neurology, vol. 60, no. 3 , p. 492-495.

TOMSON, T., NASHEF, L. and RYVLIN, P. 2008. Sudden unexpected death in epilepsy: current knowledge and future directions. Lancet Neurology, vol. 7, no. 11, p. 1021-1031.
United States Department of Health and Human Services, 2009. FDA and EPA Announce the Revised Consumer Advisory on Methylmercury in Fish. Available from: <http://www.cfsan.fda. gov/ dms/admehg3.html $>$. Access in: 21/01/2009.

XIAO, Y. and LI, X. 1999. Polyunsaturated fatty acids modify mouse hippocampal neuronal excitability during excitotoxic or convulsant stimulation. Brain Research, vol. 846, no. 1, p. 112-121.

YUEN, AW. and SANDER, JW. 2004. Is omega-3 fatty acid deficiency a factor contributing to refractory seizures and SUDEP? A hypothesis. Seizure, vol. 13, no. 2, p. 104-107.

YUEN, AW., SANDER, JW., FLUGEL, D., PATSALOS, PN., BROWNING, L., BELL, GS. and KOEPP, MM. 2008. Erythrocyte and plasma fatty acid profiles in patients with epilepsy: does carbamazepine affect omega-3 fatty acid concentrations? Epilepsy Behavior, vol. 12, no. 2, p. 317-323. 